\title{
A Critical Review of Epidemiologic Studies on Black-foot Disease
}

\author{
Yuan-Ching KO \\ Institute of Public Health, College of Medicine, National Taiwan University, Taipei, Taiwan, ROC
}

\begin{abstract}
An endemic disease in Taiwan named "Black-foot Disease", which has been researched since 1958 and about which many papers have been published, was considered caused by arsenic poisoning from artesian well water. In the beginning some information related to the disease before 1958 is introduced and then, reviews of the six papers titled "Epidemiologic Studies" on "Black-foot Disease" are made without referring to any findings from other papers. The data related to the incidence and severity of the disease from the papers are reevaluated, paying special attention to the fact that the incidence of the disease increased after the installation of pipe system water-supply to replace the artesian wells. With the abovementioned result the theory which considers arsenic poisoning as the cause of the disease, is disproved.
\end{abstract}

Key words: Black-foot Disease, arsenic poisoning, epidemiology.

(Received 15 May 1986)

\section{Introduction}

Since 1958 when the "Black-foot Disease" (Fig. 1) attracted public attention and a sytematic survey was organized, already 27 years have passed. Even with the repeated reports and the administrative efforts for its control, there seems to be little hope of the disease being eliminated in the near future. Nevertheless, in June, 1975, T. S. KO, an important participant in the control program declared an increase in the number of the patients (Ko, 1975).

The traditional name for the disease which is now called "Black-foot Disease" is "black dry snake". In Taiwanese the same word is used for panaritium and snake, and "black" and "dry" describe the condition of gangrene. Therefore, "black dry snake" is used to mean "gangrenous panaritium".

Black-foot Disease is a kind of gangrene which does not necessarily attack the foot but sometimes attacks fingers and the hand. Even when the lower extremities are attacked, usually it does not attack the whole foot in the beginning. Therefore, the name "gangrenous panaritium" seems to be more appropriated than "Black-foot Disease". The name "Black-foot Disease" does not tell the pathological entity nor the mechanism of the occurrence of the disease and contains a nuance of self-scorn and despair. So from the point of view of the medical profession it should be considered inadequate as the name of the disease. 


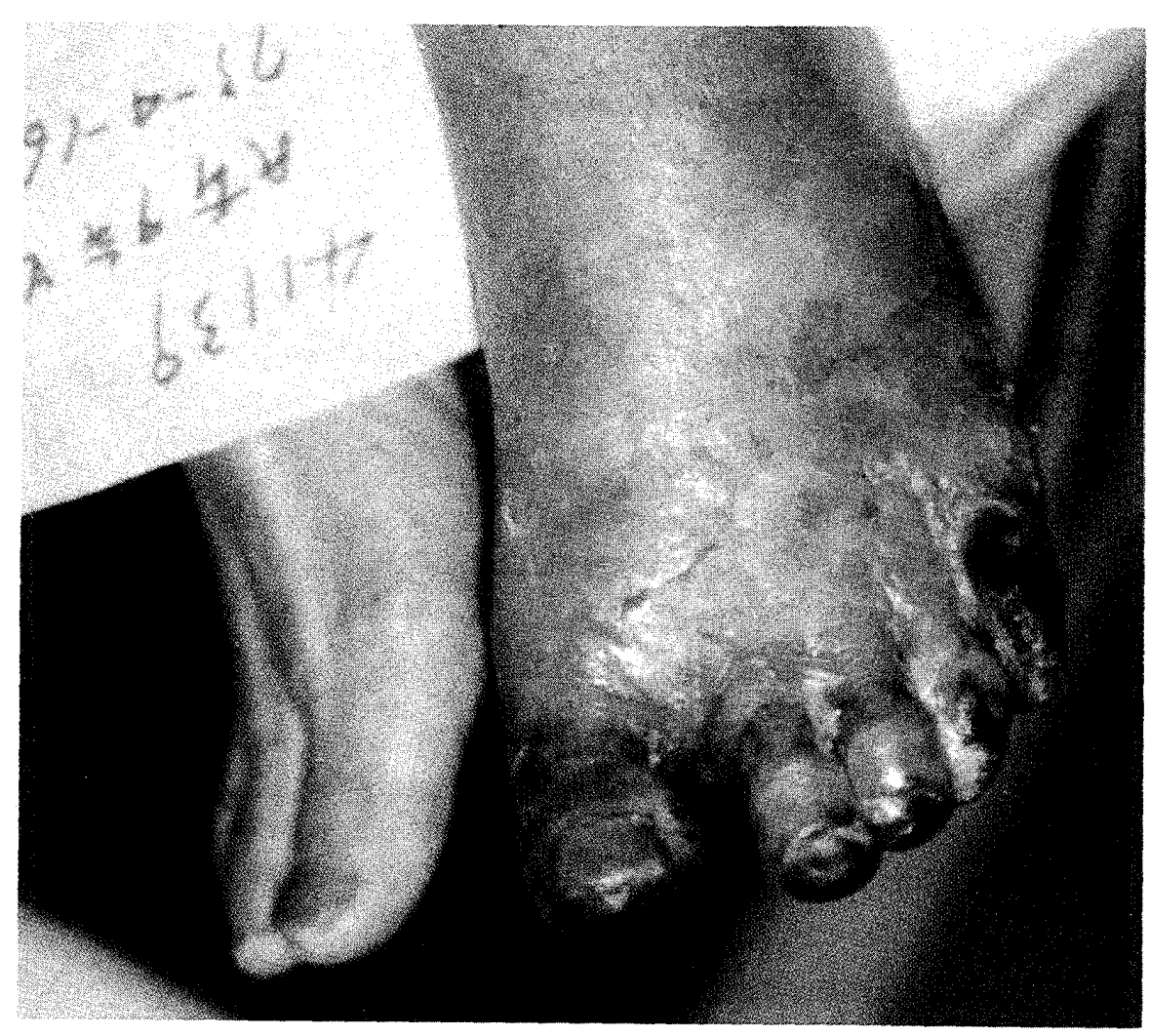

Fig. 1. A typical clinical feature (gangrene).

Kao and coworkers reported the prevalence of "spontaneous gangrene", $1.529 \%$ for male and $0.516 \%$ for female, in the Hsin-Un community of Putai township in November, 1954 (Kao et al., 1954). Even though their recognition of chronic potassium poisoning as the cause of the disease seems still not acceptable, actually the report should be considered the first report on present "Black-foot Disease".

From 1961 to 1969 , Chen and Wu reported six serial papers under the common title of "Epidemiological studies of Black-foot Disease" which have been regarded as the most important works on this disease. The authors believed arsenic to be a main cause of "Black-foot Disease".

However, I have been suspicious of this theory for a long time. In the present paper I intend to review and analyse the following papers.

1. Prevalence and incidence of the disease by age, sex, year, occupation and geographic distribution ( $\mathrm{Wu}$ et al., 1961)

The authors described four aspects from the epidemiologic point of view for their survey.

They are:

1) Case distribution by district or township, village and occupation. 
2) Case distribution in relation to income and diet.

3) In order to examine the patients in the very early stage of the disease and to follow up the disease process the authors selected primary school children for survey.

4) All cases, including suspected cases, were reported by district and village officers and were examined by the authors personally. At the same time patients' residence, sex, date of birth, date of onset of the disease, diet, kind and location of drinking water etc. were recorded and were analysed statistically.

As a result of the investigation "geographical distribution" was shown and discussed. Three hundred and twenty-seven cases were distributed in 5 districts or townships. Prevalence rate for the total area was 2.10 per thousand population. For each district or township the rate ranged from 0.14 to 5.57 per thousand population.

The prevalence rate of Putai was so high among them that some geographical points of view could have been developed from it, but the author did not mention it and only the second highest prevalence of Hsue-Chia was discussed thus denying the importance of occupational factors which were to be discussed as the next subject.

The authors stated their belief that there was no causal relationship at the beginning of the discussion on occupation. The highest prevalence rate is $19.67 \%$ of salters, the next being $9.87 \%$ of fishermen and then $3.37 \%$ of farmers. Such marked differences are interesting and should have been considered more thoroughly but the authors stated the reasons for their negligence as follows:

1) Use of artesian wells by the salters.

2) No patients in Chian-Chung, a fishing district and in Chi- $\mathrm{Ku}$, a district of salt production.

3) In Hueh-Chia, Ichu and Hsia-Ying Districts almost all of the patients were farmers but there were no patients from the farmers in Putai.

4) Even though belonging to the same village, the communities running closely along the Chian-Chun River had no patients while the communities distant from the river had some cases.

5) The two villages with the highest prevalence rates were producing salt. Both fishing villages and farming villages had the same kind of source of drinking water ... artesian . well.

Even when occupational diseases are discussed, not everyone involved in the occupation is necessarily affected by the disease but if some factors of the occupation make the disease easy to transmit or liable to occur, the situation is enough to justify the calling of the disease occupational. So the arguments made by the authors are not sufficient to deny the occupationality of the disease. Lacking insufficient data I am unable to make any deductions as to the occupationality of the Black-foot Disease but the marked difference in the prevalences of different occupational groups is still not understood regarding the emphasis on drinking water ... artesian well.

Regarding diet only the proportion of rice in the diet for both the affected and 
non-affected area was shown. The analysis shows that no significant difference can be concluded. If diet has some relationship with the incidence it does not necessarilly have to be only related with the proportion of rice. Forty per cent was used as the borderline for this consideration but neither the reason nor the method of obtaining the data was described.

Concerning monthly income, the distribution of the households into various monthly income classes for both the affected area and the non-affected area was shown. Even though the method to secure accuracy of the data and the number of persons in the households were not taken into consideration, a very clear difference was recognized between the affected area and the non-affected area. After showing this data the authors expressed many reasons for the inaccuracy of the data and denied the value of it.

About age and sex the authors insisted that the incidence rates increase with age except in the case of 70 years and over. But the data shown in the paper is nothing but the prevalence rate of each age group in the districts. So the increase of the rates means that the number of new cases (incidence) exceeds the number of deaths of the cases only. Therefore, the discussions about the similarity to thromboangitis obliterans and to arteriosclerosis need further consideration, because the confusion of incidence with prevalence seems to be the main reason for what is discussed in the paper.

Concerning the sex ratio the authors noticed that the sex ratio increased with age, from 0.51 to 6.53 , and before 20 years of age there were more female cases while after 20 years of age the male cases were more numerous. From this fact the authors concluded that some of the cases might be Raynauld' disease and guessed that the "Black-foot Disease" was a group of diseases but having the same etiology.

Regarding blood and household relations, it was indicated that 277 patients $(84.7 \%)$ are independent of both household and blood relations, 7 patients $(2.1 \%)$ are of only blood relation with other patients, 12 patients $(3.7 \%)$ are of only household relation with other patients and 31 patients $(9.5 \%)$ are of both blood and household relations with other patients. From these facts the authors believed the presence of some degree of familial occurrence but no explanation as to the reason was described.

About smoking habit, the authors gave up the possibility of computing the prevalence rates of smokers and non-smokers and drew some inference from the state of the patients. As $62 \%$ of the total patients and $93 \%$ of the female patients were nonsmokers, no significant relationship between the disease occurrence and smoking habits was concluded.

In the last part of the paper the incidence by year was discussed. It was very frankly noted that there has been a tendency of increase in the incidence of the disease from 1945 especially from 1954. "It is queer that the peak of the disease incidence was 1954-58, namely, one or two years after the piped water supply was established in the main communities". From 1942 to 1944 the number of new cases was only 10, the number from 1951 to 1953 increased to 36 and the number increased again to reach 124 
from 1957 to 1959.

2. A study of source of drinking water in relation to the disease (Chen \& $\mathrm{Wu}, 1962$ ) This study was carried out as a part of the team study by the College of Medicine, National Taiwan University, following several visits by key professors. The team study started in February, 1958 and until the publication of this paper in August, 1960 the authors still did not know the exact causal agent of the disease. Relationships between the disease and drinking water should be cited here. However, the authors hoped their report of the results so far obtained might lead to the prevention of the disease. There were two reasons why the authors believed the importance of drinking water... artesian wells.

The first lies in the following fact; in Pei-Men township there were four non-affected villages surrounded by other affected villages. At two out of the four villages the people were using shallow wells and at the remaining two villages surface water was used while at the affected villages people were using water from artesian wells.

The second reason lies in the fact that the older people of the locality associate the occurrence of the disease with the use of water from artesian wells. In 40 villages where no artesian wells were used there were no patients. In 30 villages where both artesian wells and shallow wells were used, the prevalence rate of the disease was $2 \%$. In 39 villages where only artesian wells were used the prevalence rate was nearly $5 \%$.

From these facts the authors concluded, "the occurrence of endemic Black-foot Disease is significantly related to the artesian wells". For the proof of this hypothesis the authors had investigated all of the water sources from the areas and found that out of the 988 water sources 331 were artesian wells, 577 were shallow wells or surface water and that 118 artesian wells had patients among their users,.. in other words none of the shallow wells and surface water had patients among their users. Even though without commonly used statistical analysis the association of artesian wells with the existence of patients of "Black-foot Disease" seems to be very clear.

3. Physicochemical characteristics of drinking water in endemic Black-foot Disease areas (Chen et al., 1962)

Due to the strong suspicion of the causal association of artesian well water with the occurrence of the disease, a study on the physicochemical characteristics of drinking water was started in 1959 to further clarify the relationships between agent, environment and host factors related to the disease.

Eighteen items were selected for the examination of water samples. The total number of the samples was 130; 41 from artesian wells of the endemic area, 13 from artesian wells of the nonendemic area, 15 from shallow wells in the endemic area and 61 from shallow wells in the nonendemic area. No description was made as to the unit considered to distinguish the endemic area from nonendemic area. Whether districts or vil- 
lages were considered as units was not clearly mentioned. Regarding the way of selecting the samples no descriptions were made either.

The physical characteristics of the wells were described in the following way:

1) The structures of both artesian wells and shallow wells were described in detail.

2) The water temperature of the wells was described as follows; Water temperature of shallow wells is usually two to three degrees below the atmospheric temperature. The temperature of artesian tank water is usually one degree below the air temperature but at three out of 18 wells the temperature exceeded atmospheric temperature.

3) Growth of algae was recognized in the tanks of artesian wells. The authors promised further studies for the identification of algae, on the influence of algae on the chemical components of water and on the metabolism of algae in relation to the minerals.

In the physicochemical analysis, there were no remarkable differences in $\mathrm{pH}$, bicarbonate, nitrite nitrogen, nitrate nitrogen, fluoride and carbon dioxide among the four groups of wells.

The median of turbidity was especially high in the water of artesian wells in the endemic area but this seems not to be too important because of its tremendous variety. The chloride concentration of the shallow well water was significantly higher than that of artesian well water. The chloride concentration of the water from the same kind of wells correlated with the distance of the well from the seashore more than with the endemicity of the location.

Ammonia nitrogen content of artesian well water was much higher than that of shallow well water. But no difference was recognized between the artesian wells located in the endemic area and those located in the nonendemic area.

Total hardness, total solids, calcium, magnesium, manganese seem to be higher in shallow wells than in artesian wells. However, only the ranges of these indices were shown in the paper.

The differences in the concentration of iron and arsenic of the artesian well water between the endemic area and the nonendemic area seem to be significant but in the use of median instead of mean and standard deviation the significance cannot be proved. The numbers of specimens are the same for turbidity, bicarbonate, carbon dioxide, $\mathrm{pH}$, chloride, ammonia nitrogen, nitrate nitrogen, total hardness, and total solids but for other items the numbers were smaller and the reason for the difference in the number of specimens was not mentioned.

In the beginning of the discussion the authors mentioned the suspicion that the quality of water used by the patients before may not be the same as at present. Even the nonendemic township where they obtained the specimen became the objective of their skepticism. At the same time they emphasized that the samples from the artesian wells in the nonepidemic area and shallow wells in the endemic area taken over a three-year period of investigation for this paper were too small to draw a conclusion. 
To support the meaning of their data of arsenic they referred to Blackwell's data (1961). They emphasized the suspicion that "high arsenic content in artesian well water is a main cause of Black-foot Disease" after referring to Butzengeiger's report (1940).

The authors paid attention to the high iron content in artesian well water from the endemic area and cited that usually shallow well water was richer in iron than artesian well water, but nothing could be mentioned definitely.

For the consideration of arsenic and algae some reports were referred to but all of these reports were not related to Black-foot Disease.

On the basis of above-mentioned observations and discussions the authors advanced the possible causal factors of Black-foot Disease in artesian well water as follows:

1) High arsenic content.

2) Metabolic process in algae.

3) Unknown organic toxin produced by algae.

4) Unknown chemical substances in artesian well water.

After a three year investigation, at the end of this paper the authors said, "Although this is a preliminary report, it is hoped that the result and its discussion would throw some light on the clarification of environmental factors".

4. Relation of disease process with host and environmental factors (Chen \& $\mathrm{Wu}, 1965$ )

This study was conducted with the purpose of exploring a new method of clinical epidemiology for various chronic diseases and to clarify the facts related to host, environment, severity and stage of pathogenesis.

Up to February, 1964, 530 cases had been registered. In other words, from August, 1960, when the total number of registered patients was 327, to February, 1964, 203 cases were added to the registration.

The authors consider that the severity of the disease depends on host factor, duration of artesian well water intake and the period of disease process. All cases were classified into mild, severe and fatal cases. Either mild or severe cases were subclassified into three stages. The patients who died during the period from 1958 to February 1964 were included in the fatal cases.

The cause of death can be various from the point of view of the disease. For the patients the mortality rate can be high for the older group. However, the authors did not comment on these points.

The duration of drinking artesian well water, which was represented by the duration of living at the same place, was used as a factor for discussion. If arsenic is an important factor for Black-foot Disease as suspected by the authors, the concentration of arsenic in the water should have been multiplied for the discussion.

The members from the group who suffered from this disease for less than 4 years consisted of $33.9 \%$ of dead cases and $49.7 \%$ of mild cases. If compared with other groups the fatality rate is significantly higher. This fact seems to tell the acute character 
and the high fatality among new patients.

The authors emphasized that the group who had taken artesian well water for more than 50 years had more fatal cases and fewer mild cases. With the data shown, the authors said that the longer the patients had drunk artesian well water the more severe the disease became and that this phenomenon was particularly remarkable within the first four years after the onset. However, actually the percentage of mild cases is larger for the 30-49 years group than for the 0-29 years group and the fatality is less for the 3049 years group than the $0-29$ years group among the groups of less than 4 years after onset.

Under the title "Degree of severity in relation to duration of water intake and period of disease process" the authors said, "The differences of the degree of the severity among different periods of disease process are significant in all three groups for the different duration of water intake". The severity is classified with the extent of amputation. An amputation is made by surgical operation so that the influence of their social circumstances and opportunities of medical interferences might have had some influences on the data.

As to "severity of disease by sex", all female patients are usually milder than male patients. However, for the group of $0-29$ years water intake group, more fatalities and fewer mild cases are listed for females. This exception seems to be an irony to the authors' deduction that the severity correlates only with the artesian well water. The authors tried to escape from the irony with the following comment: "younger females seem to be more sensitive to agent factors or to have more favorable environmental conditions for host-agent interaction than young males have". In this paper they limited their observation to the cases, nominator, and nothing was done as to the denominator, the population.

Secondly, the purpose of the paper was to find out some facts on the relationship between host and environmental factors at the stage of pathogenesis. As host factors, only sex was discussed, and as for age of the patient not a word was mentioned. As environmental factors, only drinking of artesian well water was repeatedly mentioned and other possible factors were forgotten.

In relation to the third purpose of the paper, at the end of summary and conclusion the authors said, "This method of clinical epidemiological study seems to be very helpful for the clarification of the characteristics of the disease process of Black-foot Disease in relation to host and environmental factors" but continued, "although the findings might only supply some clues for further investigations".

5. Statistical analysis of mortality and cause of death in the endemic area $(\mathrm{Wu} \&$ Chen, 1965)

The authors intended to analyse the mortality and cause of death in the endemic area and its adjacent nonendemic area and to find whether there were any remarkable differ- 
ences between the two adjacent areas.

The materials were data filled in on the death registration forms from 1952 to 1961. As the endemic area the Putai, Pei-Men, Hsueh-Chia districts were used. As the nonendemic area, only the Chiang-Chun District was adopted.

At first a comparison was made between the three endemic districts and the nonendemic Chiang-Chun District.

The period of observation, from 1952 to 1961, ten years in total, was divided into two parts. As the pipe system of water supply was started in 1956, the end of 1956 was adopted as the border between the two parts. The authors expected that the influence of the change in water supply would appear in the results. Considering the circumstances and the convenience of their study, age was classified into 6 categories and the cause of death was classified into 12 categories.

1) Crude death rate:

For 1952-56 the rate of the non-affected area was 8.9 per 1000 and that of the affected area was 10.1. For 1957-61 the rate of the non-affected area was 7.4, decreased by $17 \%$, while that of the affected area was 9.2 , decreased by $9 \%$. So the authors concluded the change of wate supply did not influence the disease.

2) Age specific death rate:

For 1952-56 the age specific death rate of the non-affected area was smaller than the affected area for each of the age groups of older than one year. The proportion of the rate for the affected area to the non-affected area was 0.88 for zero year, 1.00 for 1-4 year and for other groups it ranged from 1.17 to 1.70. For 1957-61 the same rates of 1 to 64 year groups for the non-affected area decreased by nearly one third while those for the affected area did not decrease so much, except for the 5-24 year group. The authors "guessed" this fact may indicate that the improvement of the water supply made the greatest contribution to the betterment in health for the $5-24$ year group.

3) Cause specific death rate:

To discuss this rate the authors quoted the possible results of chronic arsenic poisoning and confined their observations to the categories which show the same symptoms as arsenic poisoning.

As to neoplasma, excluding liver neoplasma, the rate of the non-affected area was 26.2 for 1952-56 while that of the affected area was 48.0. For 1957-61 the same rate for the non-affected area was 33.9 while that of the affected area increased to 67.8.

In regard to vascular lesions of central nervous system, because two-thirds of black foot biopsy cases showed arteriosclerotic changes, the authors expected that the development of Black-foot Disease was clearly related to arteriosclerosis and then also to vascular lesions of the central nervous system. But the rate for the affected area was only around 1.20 times that of the non-affected area, showing no remarkable change between the two periods of observation. 
Regarding cardiovascular diseases, the rate of the non-affected area for 1952-56 was 38.3 while that of the affected area was 50.4 (1.32 times). For 1957-61 the rate of the non-affected area decreased to 25.5 and that of the affected area increased to 55.9 (2.19 times).

As for liver diseases, the authors mentioned "almost the same things as the cardiovascular disease were observed".

Regarding disease of the urinary system, the rate of non-affected area was 41.8 for 1952-56 while that of affected area was 46.9. For 1957-61 the rate of the non-affected area decreased to 18.3 while that of the affected area decreased to 29.1. So the decrease ratio in the affected area is less than that in the non-affected area. Regarding the above-mentioned findings the authors said, "This seems contrary to our preliminary supposition that the piped water supply will make a considerable improvement in these rates. Perhaps only a five year lapse of time is not enough to prove our supposition, and a much longer lapse of time will be needed".

6. Effect of the piped water supply on occurrence and disease progress of Black-foot Disease (Chen \& Wu, 1969)

At the beginning the authors introduced the disease as "regarded as one of the syndromes of chronic arsenic poisoning caused by drinking artesian well water with high content of arsenic". Then, they said, "The objective of this study is to find out whether or not there have been any changes in the occurrence and severity of Black-foot Disease since piped water supply was established". "If original artesian well water is really the source of infection for Black-foot Disease and the duration of drinking tap water is long enough, the occurrence and severity of disease in tap water areas should be less than in artesian well areas".

Table 1 shows that the number of patients, who became ill in 1956 or before, was 235. One hundred and sixty two of them were from the Group A where a piped water supply system was installed in the period from 1956 to 1960 and the remaining 73 were from the Group B were the installation had not taken place until the end of 1960 . The authors thought the proportion to be constant enough for the two areas to have new

Table 1. Incidence of Black-foot Disease by year of establishment of running water supply

\begin{tabular}{|c|c|c|c|c|c|c|c|c|c|c|c|c|}
\hline Sex & \multicolumn{4}{|c|}{ Male $^{1\rangle}$} & \multicolumn{4}{|c|}{ Female $^{2\rangle}$} & \multicolumn{4}{|c|}{ Total $^{3)}$} \\
\hline \multirow[b]{2}{*}{$\begin{array}{l}\text { Groups of } \\
\text { water supply }\end{array}$} & \multicolumn{12}{|c|}{ Year of onset } \\
\hline & $\begin{array}{l}1956 \\
\text { and } \\
\text { before }\end{array}$ & $\begin{array}{c}1957 \\
1 \\
1961\end{array}$ & $\begin{array}{c}1962 \\
1 \\
1968\end{array}$ & Sum & $\begin{array}{l}1956 \\
\text { and } \\
\text { before }\end{array}$ & $\begin{array}{c}1957 \\
\mid \\
1961\end{array}$ & $\begin{array}{l}1962 \\
1968\end{array}$ & Sum & $\begin{array}{l}1956 \\
\text { and } \\
\text { before }\end{array}$ & $\begin{array}{c}1957 \\
! \\
1961\end{array}$ & $\begin{array}{c}1962 \\
\mid \\
1968\end{array}$ & Sum \\
\hline $1956-1960(\mathrm{~A})$ & 109 & 91 & 46 & 246 & 53 & 76 & 30 & 159 & 162 & 167 & 76 & 405 \\
\hline 1961 and after (B) & 39 & 55 & 65 & 159 & 34 & 44 & 58 & 136 & 73 & 99 & 123 & 295 \\
\hline Total & 148 & 146 & 111 & 405 & 87 & 120 & 88 & 295 & 235 & 266 & 199 & 700 \\
\hline
\end{tabular}

Test of significance: ${ }^{1)} \chi^{2}=26.594, P<0.001,{ }^{2)} \chi^{2}=18.926, P<0.001,{ }^{3)} \chi^{2}=45.738, P<0.001$. 
cases. However, actually Group A is made up of the main communities where the living standard and sanitary situations were better than Group B. So it is probable that many patients in Group A might have lived long enough to have their name listed by the surveyers while many patients in Group B might have died before the first survey or might have been neglected due to inconvenient communication. Just because $123 \times$ $162 / 73=273,273-76=197$, the authors concluded that there was a reduction of nearly 200 patients during the periods of 1962 and 1968 due to the change of water supply. For calculating incidence, the population always has to be taken into consideration and it must be remembered that population is changeable due to the development of the communities.

With the data shown in Table 2 the authors insisted that during the period of 1956 and before there was no statistical difference of age distribution between the $\mathrm{A}$ and $\mathrm{B}$ groups while there were more younger patients in Group B than in Group A during the two later periods. Regarding the patients from 1956 and before, the start of the piped water supply system did not influence their incidence. For the patients of 1957-1961 from Group B neither the start of the piped water supply system in 1961 nor after can not have had any influence on their incidence. If the data of the 1956 and before group be pooled and compared with the data of 1957-1961 from Group B, the proportion of the

Table 2. Incidence of Black-foot Disease by age between two different water supply

\begin{tabular}{|c|c|c|c|c|c|c|c|c|c|c|c|c|}
\hline \multirow[b]{3}{*}{$\begin{array}{l}\text { Groups of } \\
\text { water supply }\end{array}$} & \multicolumn{12}{|c|}{ Year of Onset } \\
\hline & \multicolumn{3}{|c|}{ (1) 1956 and Before } & \multicolumn{3}{|c|}{ (2) $1957-1961$} & \multicolumn{3}{|c|}{ (3) $1962-1968$} & \multicolumn{3}{|c|}{ (4) $1957-1968$} \\
\hline & Young* & Old $^{* *}$ & Sum & Young & Old & Sum & Young & Old & Sum & Young & Old & Sum \\
\hline & \multicolumn{12}{|c|}{ Male } \\
\hline $1956-1960(\mathrm{~A})$ & 53 & 56 & 109 & 21 & 70 & 91 & 5 & 41 & 46 & 26 & 111 & 137 \\
\hline 1961 and after (B) & 18 & 21 & 39 & 21 & 34 & 55 & 22 & 43 & 65 & 43 & 77 & 120 \\
\hline \multirow[t]{2}{*}{ Total } & 71 & 77 & 148 & 42 & 104 & 146 & 27 & 84 & 111 & 69 & 188 & 257 \\
\hline & \multicolumn{12}{|c|}{ Female } \\
\hline $1956-1960(\mathrm{~A})$ & 36 & 17 & 53 & 28 & 48 & 76 & 10 & 20 & 30 & 38 & 68 & 106 \\
\hline 1961 and after (B) & 26 & 8 & 34 & 22 & 22 & 44 & 20 & 38 & 58 & 42 & 60 & 102 \\
\hline \multirow[t]{2}{*}{ Total } & 62 & 25 & 87 & 50 & 70 & 120 & 30 & 58 & 88 & 80 & 128 & 208 \\
\hline & \multicolumn{12}{|c|}{ Total } \\
\hline $1956-1960(\mathrm{~A})$ & 89 & 73 & 162 & 49 & 118 & 167 & 15 & 61 & 76 & 64 & 179 & 243 \\
\hline 1961 and after (B) & 44 & 29 & 73 & 43 & 56 & 99 & 42 & 81 & 123 & 85 & 137 & 222 \\
\hline Total & 133 & 102 & 235 & 92 & 174 & 266 & 57 & 142 & 199 & 149 & 316 & 465 \\
\hline
\end{tabular}

${ }^{*}$ Young: Before 40 years old ${ }^{* *}$ Old: 40 years and over

Test of significance:

(1) Male: $\chi^{2}=0.139, P>0.9$, Female: $\chi^{2}-0.959,0.5>P>0.3$, Total: $\chi^{2}=0.727,0.5>P>0.3$

(2) Male: $\chi^{2}=3.551,0.10>P>0.05$, Female: $\chi^{2}=2.365,0.2>P>0.1$, Total: $\chi^{2}=5.768, P<0.001$

(3) Male: $\chi^{2}=7,287, P<0.001$, Female: $\chi^{2}=0.000, P=1.00$, Total: $\chi^{2}=5.091,0.005>P>0.01$

$(2)+(3)$ Male: $\chi^{2}=9.636, P<0.001$, Female: $\chi^{2}=0.732,0.5>P>0.30$, Total: $\chi^{2}=7.760, P<0.01$ 
young group is significantly larger in the 1956 and before group. Probably the loss of data concerning the elderly group is the most adequate reason to justify this difference. Because the life expectancy of the old patients must be shorter, before the first survey in 1958 some old patients who became ill before 1956 might already have died and some might have failed to be listed by the surveyers for the unco-operative attitude of the patients. So the comparison with the 1956 and before group is not reasonable. This condition can exist for both males and females but the tendency might be lighter for males than for females. So the statistical analysis does not show a significant difference for males.

For the delicate position of elderly female patients in their own families, the tendency of their refusal to answer or escape from surveyers' investigations seems quite understandable. The co-operation of patients can be obtained only when they can expect something that will better their lives.

For the 1957-61 group the distribution of age in Group B can be considered free from the influence of the change of water supply, while in Group A the influence can exist. So as calculated by the authors $\chi^{2}=5.768 \quad P<0.01$ for the 1957-1961 onset group, total in Table 2, the incidence in the old group is significantly higher for Group A. This fact seems to have some connection with the "trick of the ghost of artesian wells".

For the 1962-68 groups, the latest change in water supply could be at the end of 1960 for Group A and the earliest incidence could be at the beginning of 1962, the ghost trick effect cannot be denied. Some parts of Group B might not have had a piped water supply. So the relation between Group A and Group B is different from that shown for $1957-61$.

If the 1957-61 groups from Group B represent the situation without change in water supply, the comparison with the 1962-68 groups may be interesting. The latter group had a very significant larger proportion of elderly new cases.

If the 1962-68 groups from Group B be compared with the 1957-61 groups from the same Group, the proportion of the elderly group is always larger but no significant difference can be concluded probably because some part of Group B had not changed yet and the influence of the change in water supply was not significant enough.

The authors said that there were no cases younger than 20 years of age from Group A while there were 12 cases from Group B during the period of 1962-1968. This fact can be understood with the ghost trick epidemic in Group B and the phase after the epidemic in Group A.

By comparing the condition of May, 1968 with the record of August, 1965, 351 patients were classified under, no change and worse. With the data shown in Table 3 the authors insisted that there were more cases of no change and less cases of worse in Group A than in Group B and this phenomenon was seen in those patients who became ill during the period of 1957 and 1965 . For the above-mentioned analysis the cases who 
died in the period between August, 1965 and May, 1968 were removed from consideration. So I do not think it perfect enough. However, with the hypothesis of the "ghost trick effect" the facts mentioned by the authors can be reasonably explained. Because the duration from the end of 1960 to August, 1965 is 4 years and 7 months, the ghost trick epidemic for Group A might have reached or at least come near to the end while for the Group B the period from August, 1965 to May, 1968 could be still in the midst of the epidemic. The disease may not be an infectious disease but the manifestation of a kind of poisoning. So for Group B the proportion of the patients becoming severer would be naturally larger than that in Group A. About the fact that the above-mentioned phenomenon was seen in those patients who became ill during the period of 1957 and 1965, I have a different view.

As shown in Table 4 for each of the groups the proportion of the number of worse

Table 3. Change of disease process by sex between two different water supply areas

\begin{tabular}{|c|c|c|c|c|c|c|c|c|c|c|}
\hline \multirow{3}{*}{$\begin{array}{l}\text { Yearof } \\
\text { Onset }\end{array}$} & \multirow{3}{*}{$\begin{array}{l}\text { Groups of } \\
\text { water supply }\end{array}$} & \multicolumn{3}{|c|}{ Male } & \multicolumn{3}{|c|}{ Female } & \multicolumn{3}{|c|}{ Total } \\
\hline & & \multicolumn{9}{|c|}{ Disease process } \\
\hline & & $\begin{array}{l}\text { No } \\
\text { change }\end{array}$ & Worse & Sum & $\begin{array}{c}\text { No } \\
\text { change }\end{array}$ & Worse & Sum & $\begin{array}{c}\text { No } \\
\text { Change }\end{array}$ & Worse & Sum \\
\hline (1) & $1956-1960(\mathrm{~A})$ & 47 & 11 & 58 & 28 & 5 & 33 & 75 & 16 & 91 \\
\hline \multirow{2}{*}{$\begin{array}{c}1956 \text { and } \\
\text { before }\end{array}$} & 1961 and after (B) & 14 & 8 & 22 & 18 & 5 & 23 & 32 & 12 & 45 \\
\hline & Total & 61 & 19 & 80 & 46 & 10 & 56 & 107 & 29 & 136 \\
\hline (2) & $1956-1960(\mathrm{~A})$ & 45 & 10 & 55 & 55 & 4 & 59 & .100 & 14 & 114 \\
\hline \multirow{2}{*}{$\begin{array}{r}1957- \\
1965\end{array}$} & 1961 and after (B) & 28 & 24 & 52 & 40 & 9 & 49 & 68 & 33 & 101 \\
\hline & Total & 73 & 34 & 107 & 95 & 13 & 108 & 168 & 47 & 215 \\
\hline (3) & $1956-1960(\mathrm{~A})$ & 92 & 21 & 113 & 83 & 9 & 92 & 175 & 30 & 205 \\
\hline \multirow[t]{2}{*}{ Total } & 1961 and after (B) & 42 & 32 & 74 & 58 & 14 & 72 & 100 & 46 & 146 \\
\hline & Total & 134 & 53 & 187 & 141 & 23 & 164 & 275 & 76 & 351 \\
\hline
\end{tabular}

Test of significance:

(1) Male: $\chi^{2}=3.177,0.1>P>0.05$, Female: $\chi^{2}=0.507, P>0.6$, Total: $\chi^{2}=1.756,0.2>P>0.1$

(2) Male: $\chi^{2}=8.453, P>0.01$, Female: $\chi^{2}=3.167,0.1>P>0.05$, Total: $\chi^{2}=13.232, P<0.01$

(3) Male: $\chi^{2}=13.321, P<0.001$, Female: $\chi=3.292,0.1>P>0.05$, Total: $\chi^{2}=13.515, P<0.001$

Table 4. Distribution of cases by no change and worse and the proportion of worse in each group classified by the combination of year of onset and year of pipe system water supply installation for males and females

(A) Installation 1956-1960

(B) Installation 1961 and after

\begin{tabular}{ccccccccc}
\hline & & \multicolumn{3}{c}{ Male } & \multicolumn{3}{c}{ Female } \\
\cline { 3 - 8 } Onset & & No change & Worse & Total & No change & Worse & Total \\
\hline 1956 and & (A) & 47 & $11(0.189)$ & 58 & 28 & $5(0.151)$ & 33 \\
before & (B) & 14 & $8(0.3636)$ & 22 & 18 & $5(0.217)$ & 23 & 59 \\
$1957-$ & (A) & 45 & $10(0.182)$ & 55 & 55 & $4(0.068)$ & 49 \\
1965 & (B) & 28 & $24(0.461)$ & 52 & 40 & $9(0.184)$ & 49 \\
\hline
\end{tabular}


cases to the total number (shown in brackets) is always larger in Group B. As the $\chi^{2}$ value obtained was not big enough, the authors did not recognize the difference. The true reason for the $\chi^{2}$ values not being big enough seems to be that the total numbers in Group B for the groups of 1956 and before are markedly smaller, which might have been formed by excluding the dead cases.

The authors mentioned the differences between males and females very often. The reason for the differences was always the difference in host factor and the cause of their recognition was always $\chi^{2}$ values which were not big enough to conclude some difference in females while in males the difference was concluded. Host factors which are actually difficult to make further investigation protected the authors from necessary deeper thinking on the differences between the two sexes on which I am going to discuss in my next review with reference to the information from other sources.

\section{Conclusions}

As a conclusion of my review on these papers, I would like to state the following:

1) There is a very clear association of the prevalence of the disease with the artesian wells but still no proof for the association to be a causal association.

2) From the data shown in the papers, the removal of artesian wells seems to have increased the incidence and severity of the disease.

3) From the papers reviewd, there is not enough evidence that arsenic is not a main causal factor of Black-foot Disease.

\section{References}

Blackwell, R. Q., Yang, T. H. \& Ai, I. (1961): Preliminary report on arsenic levels in water and food from the endemic Black foot area. J. Formosan Med. Assoc., 60: 1139-1140.

Butzengeiger, K. H. (1940): Über perifere Zirkulationsstörungen bei chronischer Arsenvergiftung. Klin. Wochnschr., 19: 523-527.

Chen, K. P., Wu, H. Y. (1962): Epidemiologic studies on Black-foot Disease, 2. A study of source of drinking water in relation to the disease. J. Formosan Med. Assoc., 61: 611-618.

Chen, K. P., Wu, H. Y. \& Wu, T. C. (1962): Epidemiologic studies on Black-foot Disease in Taiwan, 3. Physicochemical characteristics of drinking water in endemic Black-foot Disease area. Memoirs Coll. Med. Nat. Taiwan Univ., 8: 115-129.

Chen, K. P., \& Wu, H. Y. (1965): Epidemiologic studies on Black-foot Disease in Taiwan China, 4. Relation of disease process with host and environmental factors, J. Formosan Med. Assoc., 64: 456-469.

Chen, K. P. \& Wu, H. Y. (1969): Epidemiologic studies on Black-foot Disease in Taiwan, China, 6. Effect of the piped water supply on occurrence and disease progress of Black-foot Disease. J. Formosan Med. Assoc. 68: 291-296.

Kao, T. M., Kao, S. J. \& Hou, S. T. (1954): Spontaneous gangrene and chronic potassium poisoning. J. Formosan Med. Assoc., 53: 36.

Ko, T. S. (1975): Black-foot Disease is spreading! United Daily News, June 30, p. 3. 
Wu, H. Y., Chen, K. P., Tseng, W. P. et al. (1961): Epidemiologic studies on Black-foot Disease, 1. Prevalence and incidence of the disease by age, sex, year, occupation and geographic distribution. Memoirs Coll., Med. Nat. Taiwan Univ., 7: 33-49.

Wu, H. Y. \& Chen, K. P. (1965): Epidemiologic studies on Black-foot Disease in Taiwan, China, 5. Statistical analysis of mortality and cause of death in the endemic area. J. Formosan Med. Assoc., 64: 470-484.

黒足病の疫学的研究に関する批判的文献考察

柯 源 卿

國立台湾大學醫學院 公共衛生研究所 教授

要 旨：台湾において 1958 年より黒足病として報告されてきた地方病は, 井戸水污染による砒素 中毒が原因であるとされてきた。ある機会に砒素中毒説に疑問を感じたのでその根拠と なった論文を詳細に分析した。ここでは先ず1958 年以前の関係ある情報を紹介し，その 後で「黒足病の疫学的研究」に関する6つの論文について文献的考察を行った。その中で 原著者等も認めている奇妙な現象「すなわち深井戸の使用を中止して水道を完備した後, 却って患者の発生数が増加している事実」に注目し，その事実をふまえた上で上記論文中 の患者の発生状況および悪化等の数字を再検討してみた。 その結果, 黒足病の原因として 砒素中毒説の根拠が薄弱であるという結論に達した。

J. UOEH (産業医大誌), 8 (3): 339-353 (1986) 